\title{
Effect of Different Channels on Discharge Coefficient of Labyrinth Weirs
}

\author{
Amir GHADERI ${ }^{1}$ \\ RasOul DANESHFARAZ ${ }^{2}$ \\ John ABRAHAM ${ }^{3}$ \\ Mohammadamin TORABI ${ }^{4}$
}

\begin{abstract}
In this study, the effect of channel-bed slope and non-prismatic converging channel on the discharge coefficient of labyrinth weirs is numerically investigated utilizing FLOW-3D model. Numerical simulation results show that modifying the labyrinth weir channel through both methods improves the discharge coefficient. Among the selected bed slopes and converging channel wall, the slope of $\beta=4 \%$ and angle of $\theta=10^{\circ}$ yielded the highest discharge coefficient. For a ratio $\mathrm{H}_{\mathrm{T}} / \mathrm{P}=0.1,\left(\mathrm{H}_{\mathrm{T}}\right.$ : flow height, P: weir height) the discharge coefficient and discharge rate for bed slope and convergence angle case were $19.22 \%, 23.9 \%$ and $22.28 \%, 25.91 \%$ higher than for a conventional labyrinth weir in prismatic channel, respectively. Simultaneous application of a bed slope and convergence angle significantly increases the discharge coefficient and discharge value case were $28.64 \%$ and $30.42 \%$ higher than compared to the conventional case. Therefore, changing the bed slope and wall angle of the weir channel increases the discharge coefficient and in this type of weir and these design alterations should be considered in weir design.
\end{abstract}

Keywords: Labyrinth weirs, channel bottom slope, converging channel, discharge coefficient, FLOW-3D.

Note:

- This paper has been received on October 3, 2019 and accepted for publication by the Editorial Board on March 2, 2020.

- Discussions on this paper will be accepted by September 30, 2021.

- https://doi.org/10.18400/tekderg.629128

1 University of Zanjan, Department of Civil Engineering, Zanjan, Iran - amir_ghaderi@znu.ac.ir https://orcid.org/0000-0002-8661-6302

2 University of Maragheh, Department of Civil Engineering, Maragheh, Iran - daneshfaraz@yahoo.com https://orcid.org/0000-0003-1012-8342

3 University of St. Thomas, School of Engineering, St Paul, USA - jpabraham@stthomas.edu https://orcid.org/0000-0003-4509-9641

4 Idaho State University, Department of Civil and Environmental Engineering, Pocatello, USA toramoha@isu.edu - https://orcid.org/0000-0002-5696-4939 


\section{INTRODUCTION}

Most failures in dams occur by water flow passing over the crest. Consequently, the most important factor is the insufficiency of the weir capacity. By increasing the weir crest length or the flow depth, it is possible to control large floods. Since the volume of flow passing through the weir is a function of length and shape of the crest, extensive research has been conducted on the impact of hydraulic and geometric parameters on the discharge coefficient of weirs. One of the most effective ways to increase the weir length is with non-linear designs (such as triangular, trapezoidal, and circular) which are called labyrinth weirs. These types of weirs increase capacity of passive-control spillways and reduce the required upstream head compared to linear weirs.

The majority of studies on labyrinth weirs have been conducted on the triangular and trapezoidal shapes. One of the first study on labyrinth weirs was conducted by Taylor [1]. Hay and Taylor [2] provided a method to calculate the discharge and design labyrinth weirs. Other technical research institutes like the University of Georgia and the Utah Water Research Laboratory (UWRL) conducted more comprehensive studies after 1980. Early empirical studies on these weirs were also conducted by Magalhaes and Lorena [3], Lux and Hinchliff [4] and Tullis, et al. [5]. Melo et al. [6] developed the method of Magalhaes and Lorena (1989) for labyrinth weirs located in a channel with converging walls (Figure 1). They believed that this method could be used to improve the orientation of inlet flow to the weir.

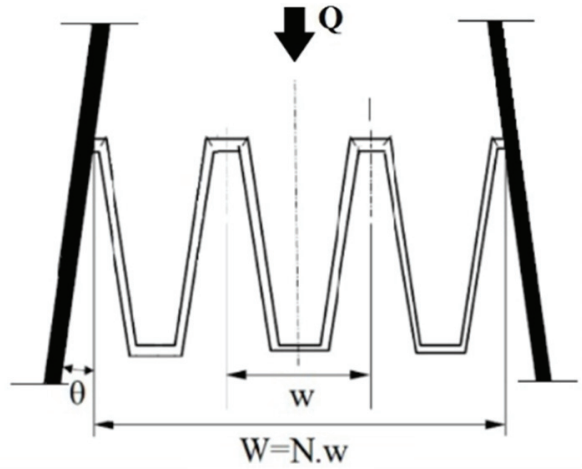

Figure 1 - Labyrinth weir in a channel with converging walls Melo, et al. [6]

In the figure, $\mathrm{W}$ is the channel width, $\mathrm{N}$ is a number of cycles of the weir, $\mathrm{w}$ is the width of each cycle, and $\theta^{\circ}$ is the divergence angle or angle of the channel wall.

The results of Tullis, et al. [7] showed that the angle of weir labyrinth with respect to the main direction of flow affects the discharge of a submerged weir. They also provided relationships for calculating the discharge over submerged labyrinth weirs. Anderson and Tullis [8] used laboratory-scale physical models to compare the hydraulic efficiency of a piano key weir design with that of a geometrically comparable rectangular labyrinth weir. Carollo, et al. [9] provided a relationship using dimensional analysis for the discharge over a triangular labyrinth weir with a sharp edge crest. Khode, et al. [10] provided another family of curves for a wider range of weir sidewall angle, the relationships can be used for designing 
labyrinth weirs. Bilhan, et al. [11] experimentally investigated the discharge capacity of labyrinth weirs with and without nappe breakers. They indicated that nappe breakers placed on the trapezoidal labyrinth weirs and circular labyrinth weirs reduced the discharge coefficient by up to $4 \%$ compared to an un-amended weir. Numerical methods have been used by various researchers in recent decades [12-17]. Shaghaghian and Sharifi [18] investigated the characteristics of flow in triangular labyrinth weirs using FLUENT. The software was able to accurately simulate flow characteristics in labyrinth weirs. Norouzi et al. [19] Investigation of Discharge Coefficient of Labyrinth Weirs with Quarter-Round Crests using Artificial Neural Networks and Support Vector Machines. The results showed that both artificial intelligent models had better accuracy in estimating $\mathrm{C}_{\mathrm{d}}$.

Despite the above studies, there is still a strong need for fundamental studies on the Geometry and approaching flow field on the hydraulic capacity of Labyrinth weirs and corresponding discharge coefficients. The principal aim of this study is to enhance the understanding of the effect of different channels on the discharge coefficient and discharge rate flow dynamics passing over the labyrinth weirs in a specified width using high-resolution, 3D free surface computational fluid dynamics. The paper starts with theoretical background of the labyrinth weirs, followed by governing equations and description of the numerical modeling. Then, details of the verification of the numerical modeling are presented against the experimental results reported by Crookston [28]. Finally and after ensuring a good agreement between experimental and numerical data, flow characteristics over the labyrinth weirs are described and effects of the effect of channel bed slope and converging channel wall on the hydrodynamics of the labyrinth weir will be analyzed.

\section{MATERIALS AND METHODS}

\subsection{Hydraulic of flow over labyrinth weirs}

The general equation for linear weirs, which was adopted by Tullis, et al. [5] for labyrinth weirs, is as follows:

$$
\mathrm{Q}=\frac{2}{3} \sqrt{2 g} C_{d} L_{c} H_{T}^{\frac{3}{2}}
$$

Where $\mathrm{Q}$ is the discharge over the weir, $\mathrm{g}$ is the acceleration due to gravity, and $\mathrm{C}_{\mathrm{d}}$ is a dimensionless discharge coefficient. Figure 2 is presented which displays annotations of relevant parameters for a weir.
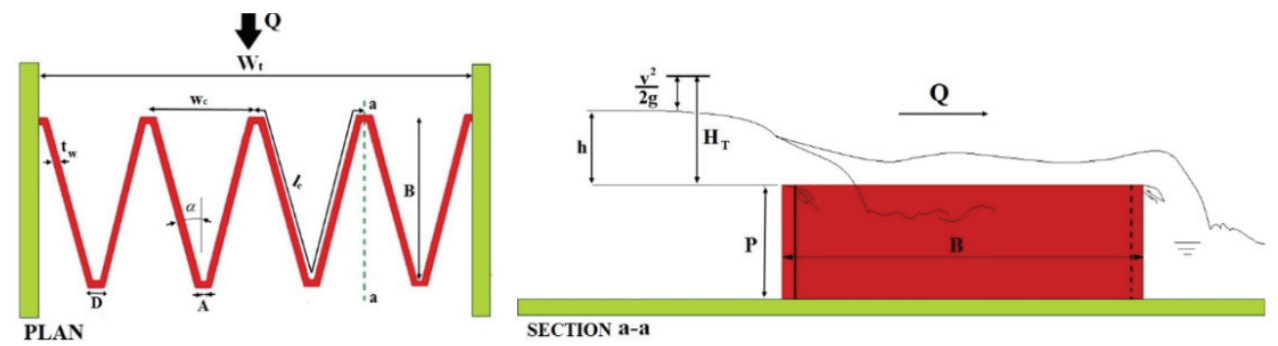

Figure 2 - Parameters effective on hydraulic performance of labyrinth weir 
Aided by Figure 2, important parameters for discharge coefficient include the total head on the crest $\left(\mathrm{H}_{\mathrm{T}}\right)$, the characteristics length of weir $\left(\mathrm{L}_{\mathrm{c}}=\mathrm{N} \times \mathrm{l}_{\mathrm{c}}\right)$, height of weir $(\mathrm{P})$, width of weir $(\mathrm{w})$, the angle between weir walls $(\alpha)$, the thickness of weir wall $\left(\mathrm{t}_{\mathrm{w}}\right)$ and depth of flow $(\mathrm{y}=\mathrm{P}+\mathrm{h})$. After dimensional analysis, discharge coefficient will be obtained as a function of dimensionless parameters.

$$
\begin{aligned}
& C_{d}=f\left(H_{T}, L_{c}, P, W, \alpha, t_{w}, y\right) \\
& C_{d}=f\left(\frac{H_{T}}{p}, \frac{L_{c}}{P}, \frac{H_{T}}{W}, \frac{t_{w}}{W}, \alpha, \frac{y}{P}, \frac{y}{W}, \frac{L_{c}}{W}\right)
\end{aligned}
$$

Several researchers have recommended an upper limit of $\mathrm{H}_{\mathrm{T}} / \mathrm{P}$ for labyrinth weirs based on declining hydraulic efficiency noted in their experimental results [2].

\subsection{Governing Equations}

FLOW-3D ${ }^{\circledR}$ is a general purpose computational fluid dynamics (CFD) program for modeling a wide variety of fluid flow fluid flow problems $[13,20]$. It uses the finite volume method to solve the RANS equations (Reynolds Average Navier-Stokes) in a Cartesian, staggered grid. FLOW-3D ${ }^{\circledR}$ uses an advanced algorithm for tracking free-surface flows, TruVOF developed by Hirt and Nichols [22], in which fluid configurations are defined in terms of a VOF function $\mathrm{F}(\mathrm{x} ; \mathrm{y} ; \mathrm{z} ; \mathrm{t})$. In one-fluid problems, the air is not treated as a fluid but rather as a void, a region without fluid mass with a uniform reference pressure assigned to it. In this case, F (Fluid Fraction) represents the volume fraction occupied by the fluid: $F=1$ in cells completely filled with fluid, and $F=0$ in cells with no fluid (void regions) [22, 23-27]. The free surface is located at a position pertaining to intermediate values of $F$ (usually, where $\mathrm{F}=0.5$, but another intermediate value may be defined by the user). The following equations describe the unsteady continuity and momentum equations in the Cartesian coordinates:

$$
\begin{aligned}
& \frac{\partial U_{i}}{\partial x_{i}}=0 \\
& \rho \frac{\partial U_{i}}{\partial t_{i}}+\rho U_{j} \frac{\partial U_{i}}{\partial x_{i}}=-\frac{\partial P}{\partial x_{i}}+\frac{\partial}{\partial x_{j}}\left(\mu \frac{\partial U_{i}}{\partial x_{j}}-\rho u_{i}^{\prime} u_{j}^{\prime}\right)+\rho g_{i}
\end{aligned}
$$

In which $U_{i}$ and are average velocity and fluctuating velocities in the xi direction respectively, $\mathrm{x}_{\mathrm{i}}=(\mathrm{x}, \mathrm{y}, \mathrm{z}), \mathrm{U}_{\mathrm{i}}=(\mathrm{U}, \mathrm{V}, \mathrm{W})$, and $\mathrm{u}_{\mathrm{i}}{ }^{\prime}=\left(\mathrm{u}^{\prime}, \mathrm{v}^{\prime}, \mathrm{w}^{\prime}\right)$. The symbols $\rho, \mu, \mathrm{P}$ and $\mathrm{g}_{\mathrm{i}}$ are density, dynamic viscosity, pressure, and gravitational acceleration, respectively. Instantaneous velocity is defined as $\mathrm{u}_{\mathrm{i}}=\mathrm{U}_{\mathrm{i}}+\mathrm{u}_{\mathrm{i}}^{\prime}$ for the three directions.

A turbulence model is necessary in order to account for the nonlinear Reynolds stress terms. In this study, the chosen turbulence model was (RNG) ${ }^{\dagger} \mathrm{k}-\varepsilon$, because in Flow Science, Inc. [22] is mentioned that RNG k- $\varepsilon$ model has wider applicability than the standard k- $\varepsilon$, and is usually the best choice. In particular, the mentioned turbulence model has been utilized successfully in some similar numerical studies in which the flow over a weir or under a sluice gate is simulated [24-25-26-28-29]. The k- $\varepsilon$ (RNG) turbulence model equations are referenced to Yakhot et al. studies [30].

${ }^{\dagger}$ Re-Normalization Group 


\subsection{Numerical and Experimental Model}

The results of the numerical solution were validated with experimental data of Crookstone [31]. In Table 1, the geometric characteristics of the labyrinth weir are presented.

Table 1 - Geometric characteristics of labyrinth weir, Crookston [31]

\begin{tabular}{cccccccc}
\hline Model & $\alpha\left({ }^{\circ}\right)$ & $\mathrm{P}(\mathrm{mm})$ & $\mathrm{L}_{\text {c-cycle }}(\mathrm{cm})$ & w/P & $\mathrm{N}$ & Crest & Type \\
\hline Labyrinth weir & 15 & 152.4 & 99.567 & 2.008 & 4 & QR & Trap \\
\hline
\end{tabular}

In this study, the effect of bed slope and converging channel wall on discharge coefficient and discharge rate of labyrinth weir investigated. For this purpose, the slopes of $\beta=0 \%, 1 \%$, $2 \%, 3 \%$, and $4 \%$ for the channel bed, and wall converging angles of $\theta=0^{\circ}, 5^{\circ}, 7.5^{\circ}$, and $10^{\circ}$ were used. Figures 3 and 4 shows how the slopes and convergence angles were applied to the labyrinth weir channel.
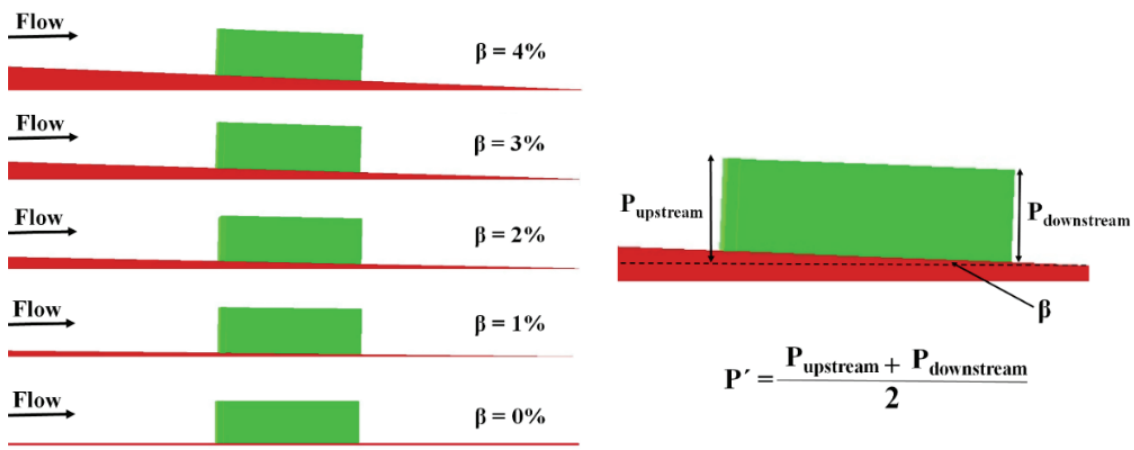

Figure 3 - Application of channel bed slope in the labyrinth weir, $\beta=1 \%, 2 \%, 3 \%, 4 \%$
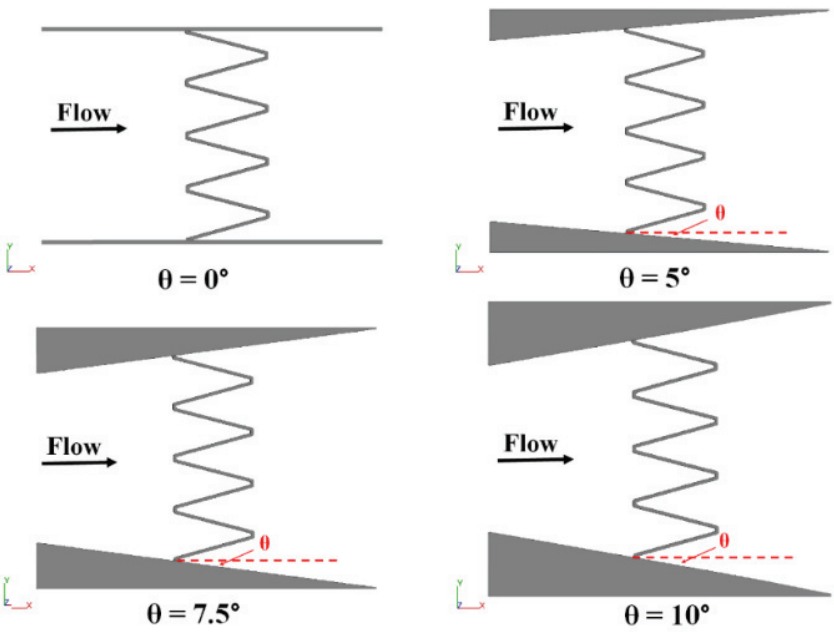

Figure 4 - Application of converging channel wall in the labyrinth weir $\theta=0^{\circ}, 5^{\circ}, 7.5^{\circ}, 10^{\circ}$ 


\subsection{Computational Mesh and Boundary Conditions}

The weir setup was performed by inserting an STL (sterolithography) file. The computational domain including boundary conditions is shown in Fig. 5. The domain was discretized using one non-uniform mesh block (see figure 6). Considering the geometry dimensions and the estimated values of $y^{+}$, Several computational meshes were utilized to select the appropriate mesh. According to the sensitivity mesh results, listed in Table 2, and by comparing the discharge coefficients obtained from the numerical solutions with experimental results, four different mesh sizes were used at the vicinity of labyrinth weir.

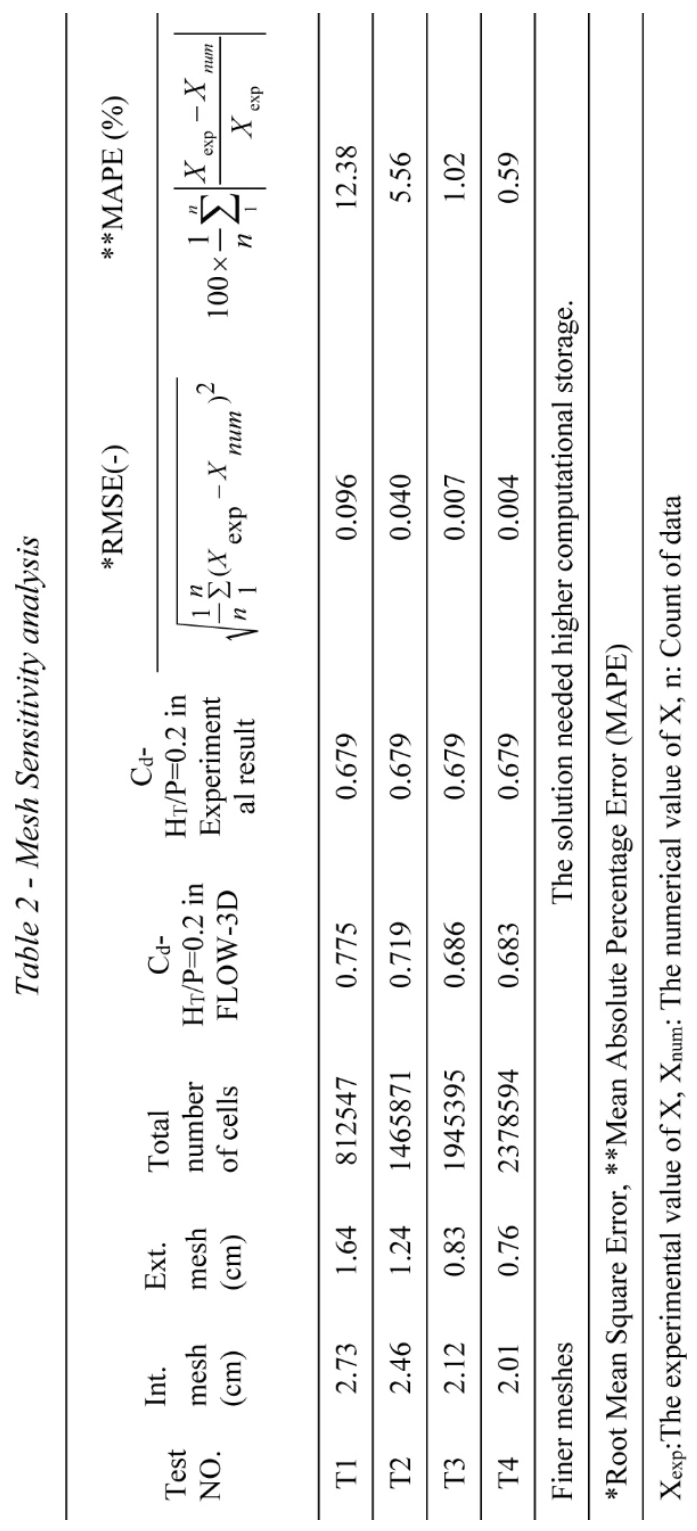


Based on this mesh-refinement study, the dimensions of the larger elements are $2.12 \mathrm{~cm}$ with a count of 547,853 cells. The size of the smaller elements are $0.83 \mathrm{~cm}$ with a count of $1,397,542$. So in total, $1,945,395$ cells were utilized to model the channel. With the selected the appropriate mesh resulting in a relative error and RMSE of 1.02\%, 0.007 and maximum aspect ratio 1.23, respectively. In this software maximum aspect ratios in $\mathrm{X} / \mathrm{Y}, \mathrm{X} / \mathrm{Z}$ and $\mathrm{Y} / \mathrm{Z}$ should be less than 4 to simulate flow pattern more precisely. This principle was considered in all runs subsequently [22]. To reduce the effect of computational mesh on simulation results the same mesh was utilized to all models of this research (Figure 5).

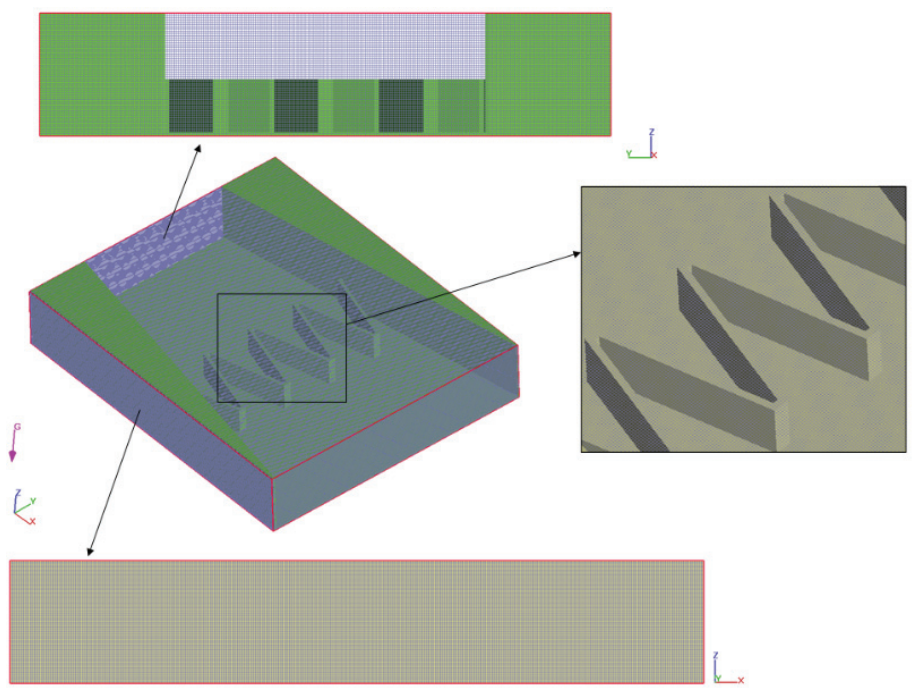

Figure 5 - Meshing in three directions $X, Y, Z$

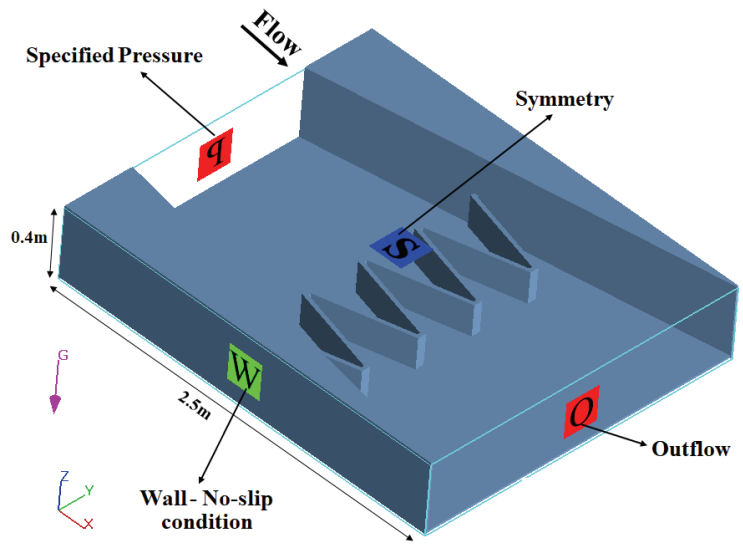

Figure 6 - Applied boundary conditions 
The lower $\mathrm{Z}\left(\mathrm{Z}_{\mathrm{min}}\right)$ and both of the side boundaries were treated as rigid wall. No-slip conditions were applied at the wall boundaries, and they were treated as non-penetrative boundaries. A law-of-the-wall velocity profile was assumed near the wall, which modifies the wall shear stress magnitude. Symmetry boundary condition is used for the $Z_{\max }$ plane, which implies that identical flows occur on the other side of the boundary. In the $\mathrm{X}_{\text {min }}$ plane, the boundary condition was specified stagnation pressure. With this algorithm, FLOW-3D ${ }^{\circledR}$ is able to model various flow heights beginning at a stagnation pressure state corresponding to the various $\mathrm{H}_{\mathrm{T}} / \mathrm{P}$ values. The upstream boundary length from the weir was $1.2 \mathrm{~m}(\mathrm{~L} \sim 8 \mathrm{P})$ and monitoring of the temporal variations of the water surface elevation at various stations downstream of the inlet boundary showed that this length is sufficient enough for an undisturbed approach flow to be established. The $\mathrm{X}_{\max }$ boundary which is located adequately far from the weir location has been considered as outflow boundary. The computed steadystate flow rate at this boundary equals the overflow capacity of the weir. Figure 6 are also included; they present the boundary conditions used for the weirs models.

\section{RESULTS AND DISCUSSIONS}

\subsection{Data Verification}

A stability criterion similar to the Courant number is used to calculate the allowed time-step size. During the iteration, the time-step size has been controlled by both of the stability and convergence criterion, which leads to time steps between 0.0001 and $0.0013 \mathrm{~s}$. The evolution in time was used as a relaxation to the final steady state. The steady-state condition was checked through monitoring the flow kinetic energy. Furthermore, the flow rate at the outlet boundary and also the free surface elevation at the inlet boundary were monitored during the simulation process. It was found that with 12-s simulation of the flow, the solution becomes fully converged and the steady-state condition is achieved for all of the $\mathrm{H}_{\mathrm{T}} / \mathrm{P}$ values. The flow over the labyrinth weir is simulated as a steady-state of flow (Figure. 7(A)), and the discharge coefficient of flow is validated with experimental data of Crookston [31]. To ensure a good agreement between the numerical and experimental data, the error was determined and is presented in Figure. 7(B).
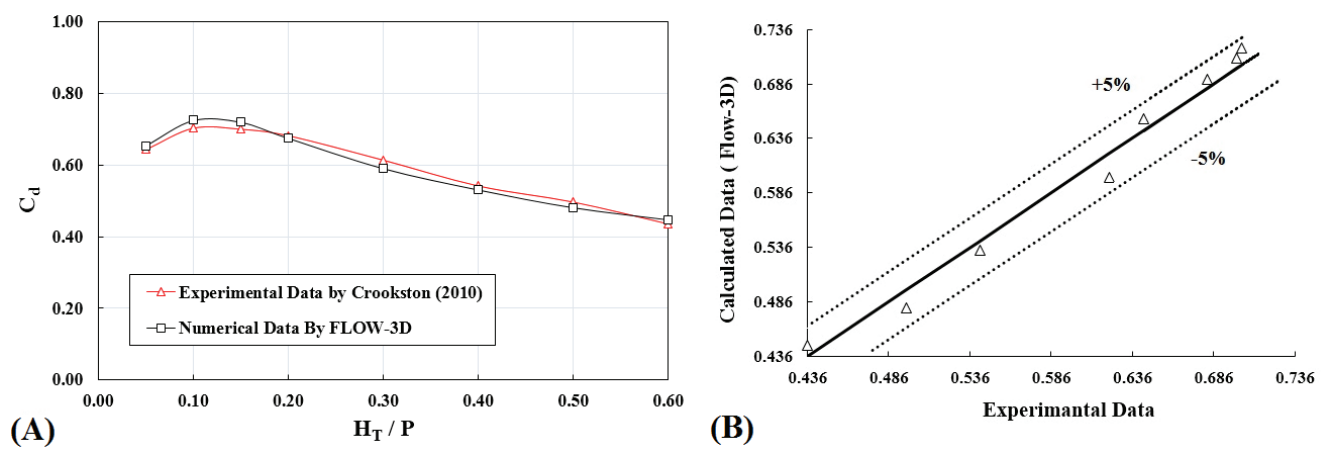

Figure 7 - (A) Comparison of discharge coefficient obtained from numerical solution with experimental data (B) Determination of the percentage of error 
It can be observed that changes in discharge coefficient obtained by software are similar to the experimental data with different $\mathrm{H}_{\mathrm{T}} / \mathrm{P}$ ratio. The discharge coefficient increases for low $\mathrm{H}_{\mathrm{T}} / \mathrm{P}$ ratio and decreases for high ratios. To compare the results of the discharge coefficient obtained from the FLOW-3D Software with the experimental data, the discharge coefficient error is calculated for different $\mathrm{H}_{\mathrm{T}}$ /P ratios according to Eq. 6 .

$$
E=\frac{\left(C d_{N}-C d_{E}\right)}{C d_{N}} \times 100
$$

In Eq. 6, $\mathrm{E}$ is the relative error percentage, $\mathrm{Cd}_{\mathrm{N}}$ is the discharge coefficient of the weir obtained by numerical solution, and $\mathrm{Cd}_{\mathrm{E}}$ is the measured discharge coefficient. The maximum percentage of error for $\mathrm{H}_{\mathrm{T}} / \mathrm{P}=0.6$ is $4.6 \%$ and the minimum value for $\mathrm{H}_{\mathrm{T}} / \mathrm{P}=0.4$ is $3.1 \%$. It can be observed that the relative error is $\pm 5 \%$ which indicates a good agreement between the numerical and experimental data.

\subsection{Discharge Coefficient of Labyrinth Weir}

Flow simulations were performed on the modified weirs using the same turbulence model, boundary conditions, and mesh. Figure 8 shows the water flow profiles over the labyrinth weir by applying bed slope and convergence angle ratio of $\mathrm{H}_{\mathrm{T}} / \mathrm{P}=0.3$.

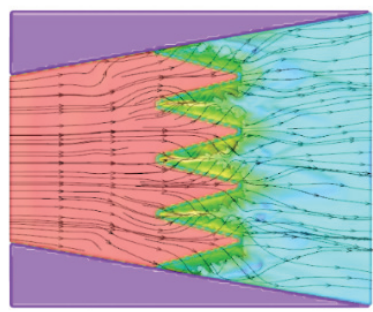

(A)

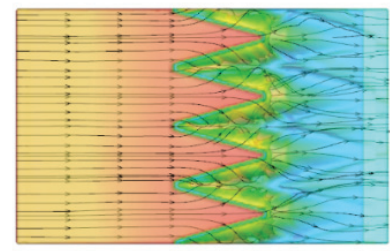

(B)
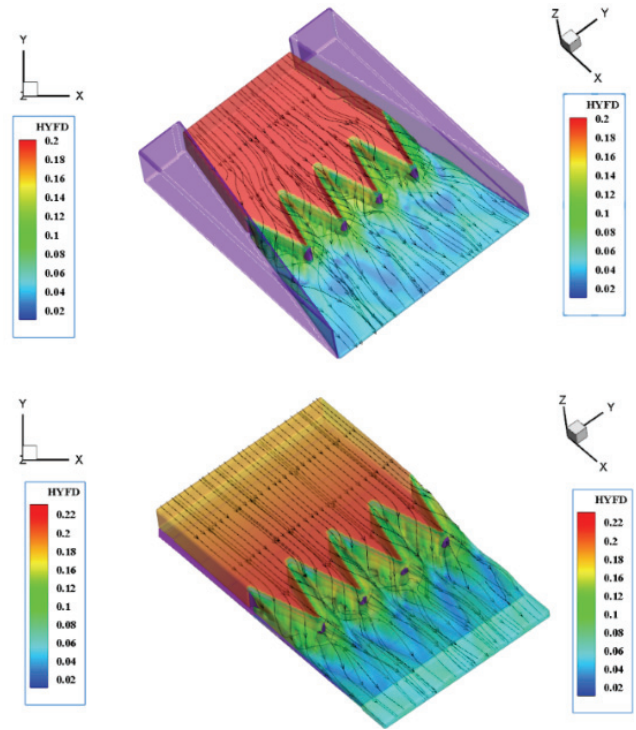

Figure 8 - Water flow profile over adjusted weirs for $H_{T} / P=0.3$

(A) Adjusting convergence angle $\theta=10^{\circ}$ (B) Adjusting bed slope $\beta=4 \%$

It is observed that the flow over the weir with the bed slope of $\beta=4 \%$ was higher than the one with a converging channel wall of $\theta=10^{\circ}$, which is due to increased flow velocity through applying bed slope. The discharge coefficients for labyrinth weirs were also calculated after 
modifying the channel bed slope and converging channel wall. Figure 9 shows the resulting values.
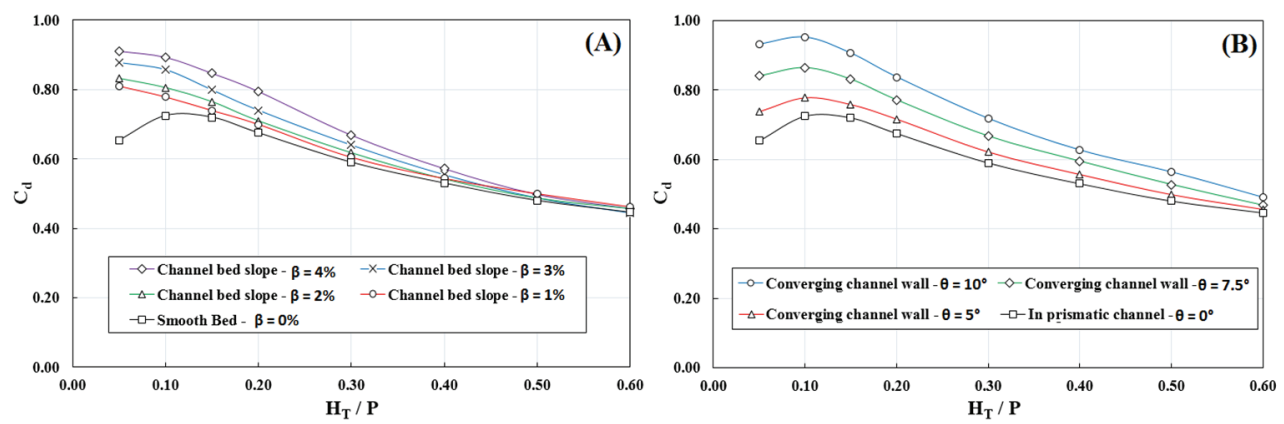

Figure 9 - (A) Discharge coefficient values after modifying channel bed slope, (B) Discharge coefficient values after modifying converging channel wall

Figure 9 indicates that, for a fixed $\mathrm{H}_{\mathrm{T}} / \mathrm{P}$ ratio, increasing the channel bed slope increases the discharge coefficient values and the difference is significant at low $\mathrm{H}_{\mathrm{T}} / \mathrm{P}$ ratios. Also for low $\mathrm{H}_{\mathrm{T}} / \mathrm{P}$ ratios, the discharge coefficients for converging channels exceeds that of prismatic channels. In addition, the discharge increases as the convergence angle increases. The effect is most pronounced at low $\mathrm{H}_{\mathrm{T}} / \mathrm{P}$ ratios. It should be noted that with an increase in $\mathrm{H}_{\mathrm{T}} / \mathrm{P}$ ratio, the discharge coefficient values have a decreasing trend which is due to submergence of the weir at higher ratios and increased flow interference. In Figure 10, a subset of results are brought together to show the effects of convergence angle and bed slope in a single figure.

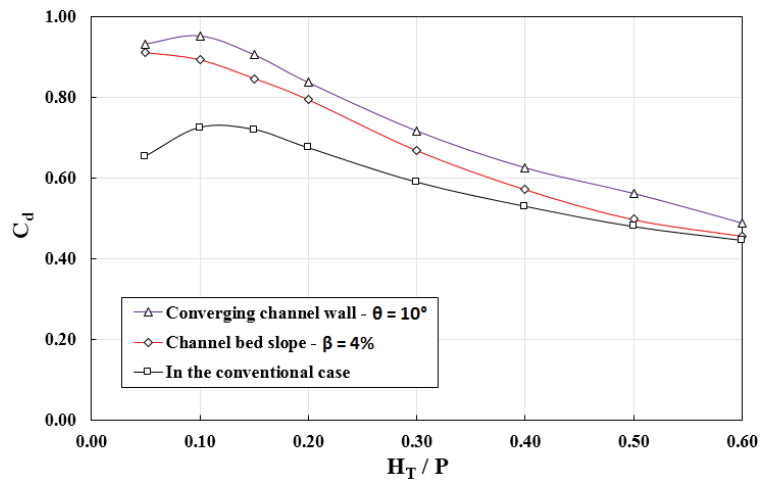

Figure 10 - Comparison of discharge coefficient values in cases with modified geometry and the conventional case

It was observed that, if bed slope and converging channel wall are modified, the discharge coefficient will be greater than the conventional case for all $\mathrm{H}_{\mathrm{T}} / \mathrm{P}$ ratios. Note that the increases in $\mathrm{C}_{\mathrm{d}}$ values are due to the improved the orientation of the flow lines to the labyrinth weir sidewall. This reduces the interference in the flow over the weir especially closer to 
perpendicular. Modifying the convergence angle was found to be more effective than the channel bed slope. $\mathrm{In}_{\mathrm{T}} / \mathrm{P}=0.1$, discharge coefficient values for the wall with an angle of $\theta=10^{\circ}$ and bed slope of $\beta=4 \%$ were $23.9 \%$ and $19.22 \%$ higher than the discharge coefficient in the conventional case in prismatic channel, respectively. This difference is reduced by increasing the $\mathrm{H}_{\mathrm{T}} / \mathrm{P}$ ratio. Figure 11 compares the discharge coefficients for a labyrinth weir with a bed slope of $\beta=4 \%$ and convergence angle of $\theta=10^{\circ}$ with the conventional case.

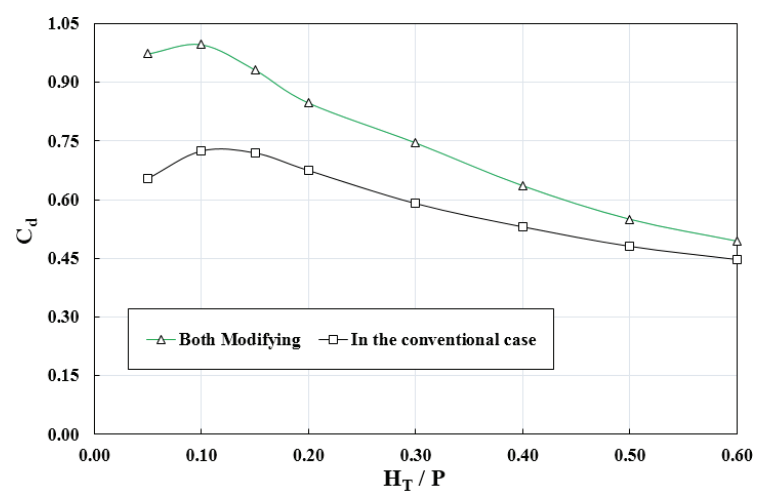

Figure 11 - Comparison of the discharge coefficient values in a case with combined bed slope and converging channel wall and the conventional weir in prismatic channel

It was observed that, for low $\mathrm{H}_{\mathrm{T}} / \mathrm{P}$ ratios, discharge coefficient values with a bed slope of $\beta=4 \%$ and convergence angle of $\theta=10^{\circ}$ were quite different from the conventional case. In $\mathrm{H}_{\mathrm{T}} / \mathrm{P}=0.1$, use of both bed-sloping and converging channel wall increased the discharge coefficient by $28.64 \%$.

\subsection{Discharge Value of Labyrinth Weir}

In labyrinth weirs, unlike linear weirs, streamlines are not perpendicular to the crest and pass the weir in various directions to reduce flow resistance [32]. A weakness of labyrinth weirs is the interference of streamlines due to flow passage over the weir, which decreases the discharge coefficient. Applying convergence angles to the labyrinth weir channel wall improves the flow lines orientation. Figure 12 presents that the flow magnification ratio for labyrinth weirs after modifying the channel bed slope and convergence angle as compared to conventional labyrinth weirs in prismatic channel.

Figure 12 shows that for a fixed $\mathrm{H}_{\mathrm{T}} / \mathrm{P}$ ratio, increasing the channel bed slope and convergence angle increases the flow magnification ratio as a reagent the discharge rate values. The effect is most pronounced at low $\mathrm{H}_{\mathrm{T}} / \mathrm{P}$ ratios. Note that a bed slope of $\beta=4 \%$ and convergence angle of $\theta=10^{\circ}$ create the maximum discharge rate for all $\mathrm{H}_{\mathrm{T}} / \mathrm{P}$ ratios. This figure also shows the submerged weir decreases flow magnification for high $\mathrm{H}_{\mathrm{T}} / \mathrm{P}$ ratios. Figure 13 shows the flow magnification ratio by applying both modifying bed slope and converging channel wall, $\beta=4 \%$ and $\theta=10^{\circ}$, compared to the conventional labyrinth weir in prismatic channel. 

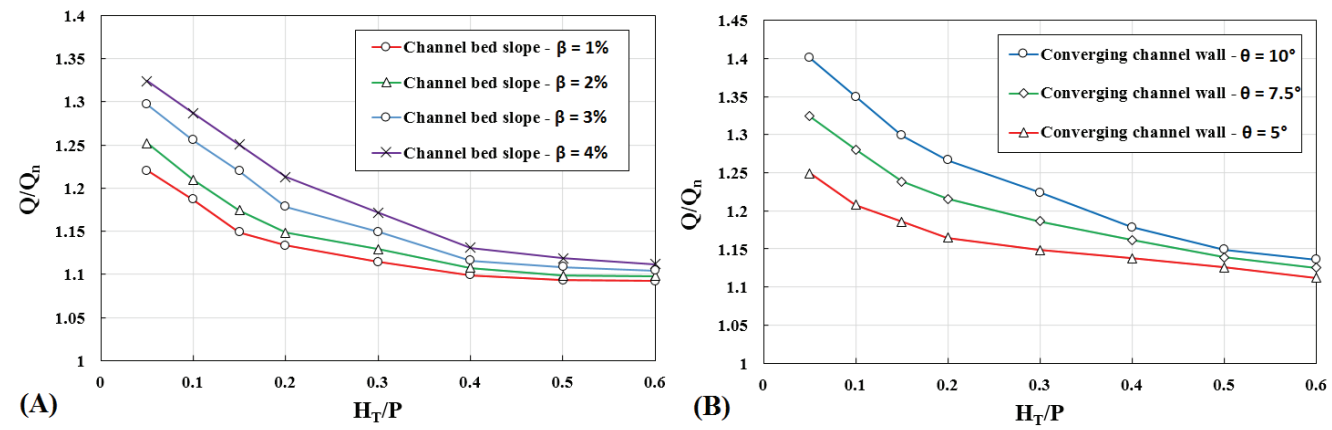

Figure 12 - The flow magnification ratio for $H_{T} / P(A)$ After modifying the channel bed slope; (B) After modifying converging channel wall

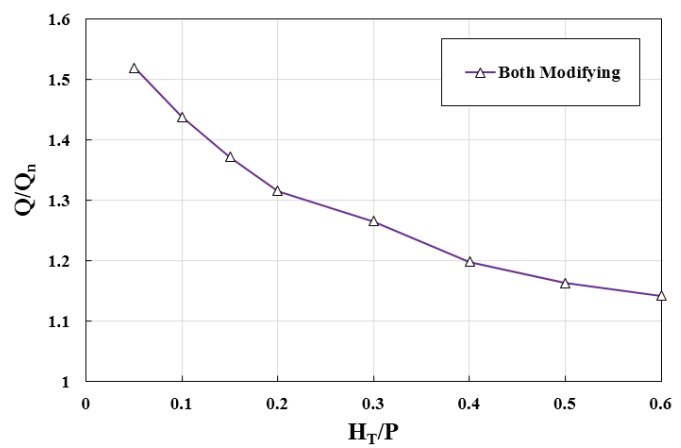

Figure 13 - The flow magnification ratio for $H_{T} / P$ by simultaneous application of both modifying

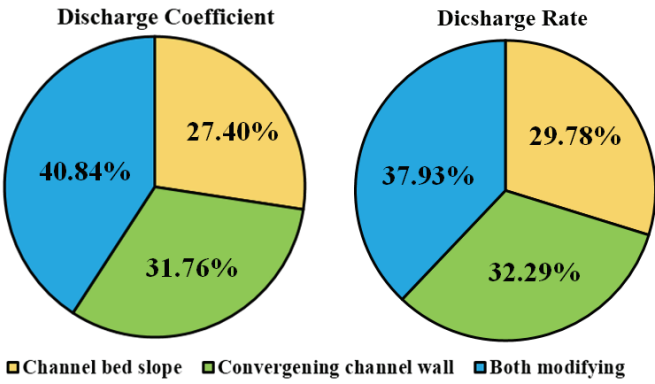

Figure 14 - Averaged contribution percentage of different components in discharge coefficient and discharge rates

The greatest difference between the discharge rates is evident at low $\mathrm{H}_{\mathrm{T}} / \mathrm{P}$ ratios, so that for example in $\mathrm{H}_{\mathrm{T}} / \mathrm{P}=0.1$ if both the bed slope and the convergence angle are modified at a same 
time, discharge rate can increases $30.42 \%$ compared to the conventional case. This can be due to improved flow orientation and, consequently, reduce flow interference while increasing velocity over the weir. According to Figure 14 and by considering all $\mathrm{H}_{\mathrm{T}} / \mathrm{P}$ ratios in different Channels, averaging the contribution percentage of converging channel wall is greater than the bed slope. There is approximately $4 \%$ difference between the two states. Simultaneous application of a bed slope and convergence angle increase the contribution of up to $40.84 \%$ and $37.93 \%$ in discharge coefficient values and the discharge rates of the flow passing over the labyrinth weir, respectively.

Therefore, the effective role of channel bed slope and converging channel wall for improving the hydraulic performance of labyrinth weirs through increasing the discharge coefficient and discharge rate should be considered in labyrinth weir design.

\section{CONCLUSION}

This study aimed to the effect of channel-bed slope and non-prismatic converging channel wall on the discharge coefficient of labyrinth weirs. The results of simulating of labyrinth weir adjusted geometry can be summarized as follows:

- The numerical and experimental data were validated; the range of relative error of discharge coefficient was $\pm 5 \%$. This finding indicates a good agreement between the numerical and experimental data.

- For a fixed $\mathrm{H}_{\mathrm{T}} / \mathrm{P}$ ratio, a bed slope or convergence angle increases the discharge coefficient and discharge value. The increase in discharge coefficient and discharge rate values is more pronounced at higher slopes and convergence angles.

- $\quad$ For $=\mathrm{H}_{\mathrm{T}} / \mathrm{P}=0.1$, the discharge coefficient and discharge rate values was $19.22 \%, 23.9 \%$ and $22.28 \%, 25.91 \%$ higher than for the conventional labyrinth weirs in prismatic channel, respectively. The increase is due to improved flow orientation and, consequently, reduced flow interference caused by increased flow velocity over the weir. The effect is smaller for larger $\mathrm{H}_{\mathrm{T}} / \mathrm{P}$ ratios, this observation is believed to be a consequence of weir submergence.

- Simultaneous application of both modifying significantly increases the discharge coefficient and discharge value compared to the conventional case. This increase, similar to the cases with only one modification, is more evident for low $\mathrm{H}_{\mathrm{T}} / \mathrm{P}$ ratios for the discharge coefficient and discharge rate. Discharge coefficients and discharge rate increased by $28.64 \%$ and $30.42 \%$ for $\mathrm{H}_{\mathrm{T}} / \mathrm{P}=0.1$, compared to conventional labyrinth weir in prismatic channel, respectively.

- Averaging the contribution percentage of show that converging channel wall is greater than the bed slope. Simultaneous application of a bed slope and convergence angle increase the contribution of up to $40.84 \%$ and $37.93 \%$ in discharge coefficient values and the discharge rates of the flow passing over the labyrinth weir, respectively.

- Results obtained by adjustment of the channel bed slope and convergence angles and through increasing discharge coefficients of the labyrinth weir agreed with those of Melo, et al. [6]. Placement of weirs inside channels with converging channel walls was one way of improving flow orientation and of increasing discharge passing over the weir. 


\section{References}

[1] Taylor, G., The performance of labyrinth weirs, PhD thesis. Univ. of Nottingham, U.K.J. 1968.

[2] Hay, N., Taylor, G., Performance and design of labyrinth weirs. ASCE, Journal of Hydraulic Engineering, Vol 96, No 11, 2337-2357, 1970.

[3] Magalhães, A., Lorena, M., Hydraulic design of labyrinth weirs. Report No. 736, National Laboratory of Civil Engineering, Lisbon, Portugal. 1989.

[4] Lux, F., and Hinchliff, D., Design and construction of labyrinth spillways. $15^{\text {th }}$ Congress ICOLD, Vol. IV, Q59-R15, Lausanne, Switzerland, 249-274, 1985.

[5] Tullis, J.P., Nosratollah, A., Waldron, D., Design of labyrinth weirs, ASCE, Journal of Hydraulic Engineering, Vol 121, No 3, 247-255, 1995.

[6] Melo, J., Ramos, C., Magalhaes, A., Descarregadores com soleira em labirinto de um ciclo em canais convergentes. Determinação da capacidad de vazão, Proc. $6^{\circ}$ Congresso da Água, Porto, Portugal, in Portuguese. 2002.

[7] Tullis, B., Young, J., Chandler, M., Head-discharge relationships for submerged labyrinth weirs. Journal of Hydraulic Engineering, Vol 133, No 3, 248-254. 2007.

[8] Anderson, R.M., Tullis, B.P., Comparison of piano key and rectangular labyrinth weir hydraulics. ASCE, Journal of Hydraulic Engineering, Vol 138, No 4, 358-361, 2011.

[9] Carollo, G.F, Ferro V., Pampalone, V., Experimental Investigation of the Outflow Process over a Triangular Labyrinth-Weir. ASCE, Journal of Irrigation and Drainage Engineering, Vol 138, No 1, 73-79. 2012.

[10] Khode, BV., Tembhurkar, AR., Porey, PD., Ingle, RN., Experimental Studies on Flow over Labyrinth Weir, Journal of Irrigation and Drainage Engineering, Vol 138, No 6, 548-552, 2012.

[11] Bilhan, O., Emiroglu, M. E., Miller, C.J., Experimental Investigation of Discharge Capacity of Labyrinth Weirs with and without Nappe Breakers. World Journal of Mechanics, Vol 6, 207-221, 2016.

[12] Daneshfaraz, R., Ghahramanzadeh, A., Ghaderi, A., Joudi, A. R., Abraham, J., Investigation of the Effect of Edge Shape on Characteristics of Flow under Vertical Gates, Journal-American Water Works Association, Vol 108, No 8, 425-432, 2016.

[13] Ghaderi, A., Dasineh, M., Abbasi, S., Abraham, J., Investigation of trapezoidal sharpcrested side weir discharge coefficients under subcritical flow regimes using CFD, Applied Water Science, Vol 10, No 1, 31, 2020

[14] Savage, B., Frizell, K., Crowder, J., Brian versus brawn: The changing world of hydraulic model studies. Proc. of the ASDSO Annual Conference, Phoenix, Ariz., CDROM, 2004.

[15] Daneshfaraz, R., Joudi, A. R., Ghahramanzadeh, A., Ghaderi, A., Investigation of flow pressure distribution over a stepped weir, Advances and Applications in Fluid Mechanics, Vol 19, No 4, 811, 2016. 
[16] Daneshfaraz, R., Minaei, O., Abraham, J., Dadashi, S., Ghaderi, A., 3-D Numerical simulation of water flow over a broad-crested weir with openings, ISH Journal of Hydraulic Engineering, 1-9, 2019.

[17] Dabling, M.R., Tullis, B.P., Modifying the downstream hydrograph with staged labyrinth weirs. Journal of Applied Water Engineering and Research, Vol 6, No3, 183-190. 2018).

[18] Shaghaghian, M.R., Sharifi, M.T., Numerical modeling of sharp-crested triangular plan form weirs using FLUENT. Indian Journal of Science and Technology, Vol 8, No, 34, 1-7. 2015.

[19] Norouzi, R., Daneshfaraz, R., Ghaderi, A., Investigation of discharge coefficient of trapezoidal labyrinth weirs using artificial neural networks and support vector machines. Applied Water Science, Vol 9, No 7, 148. 2019.

[20] Daneshfaraz, R., Ghaderi, A., Ghahremanzadeh, A. An analysis of flowing pattern around T-shaped Spur Dike at 90 Arc, based on Fluent and Flow-3D Models. International Bulletin of Water Resources and Development, Vol 3, No 3, 19. 2015 .

[21] Hirt, C. W. and Nichols, B. D., Volume of Fluid (VOF) method for the dynamics of free boundaries. Journal of Computational Physics, 39:201-225, 1981.

[22] Flow Science, Inc. FLOW-3D User Manual. Version 11.0.3, Santa Fe, New Mexico, USA, 2014.

[23] Ghaderi, A., Abbasi, S. CFD simulation of local scouring around airfoil-shaped bridge piers with and without collar. Sādhanā, Vol 44, No, 10, 216, 2019.

[24] Zahabi, H., Torabi, M., Alamatian, E., Bahiraei, M., Goodarzi, M. Effects of Geometry and Hydraulic Characteristics of Shallow Reservoirs on Sediment Entrapment. Water, Vol 10, No 12, 1725, 2018.

[25] Seo, I.W., Do Kim Y., Park Y.S., Song C.G., Weir discharges by modification of weir shapes and overflow surroundings, Environmental Earth Sciences, Vol 75, No 6, 496, 2016.

[26] Daneshfaraz, R., Ghaderi, A., Numerical Investigation of Inverse Curvature Ogee Weir, Civil Engineering Journal, Vol 3, No 11, 1146-1156, 2017.

[27] Daneshfaraz, R., Sadeghfam, S., Ghahramanzadeh, A., Three-dimensional numerical investigation of flow through screens as energy dissipators. Canadian Journal of Civil Engineering, Vol 44, No 10, 850-859, 2017.

[28] Ghaderi, A., Dasineh, M., Daneshfaraz, R., Abraham, J., Reply to the discussion on paper: 3-D numerical simulation of water flow over a broad-crested weir with openings by Daneshfaraz et al., 2019, in ISH journal of hydraulic engineering, DOI: 10.1080/09715010.2019. 1581098. ISH Journal of Hydraulic Engineering, 1-3, 2020.

[29] Ghaderi, A., Abbasi, S., Abraham, J., Azamathulla, H.M., Efficiency of trapezoidal labyrinth shaped stepped spillways. Flow Measurement and Instrumentation, 101711, 2020. 
[30] Yakhot, V., Orszag, S.A., Thangam, S., Gatski, T.B., Speziale, C.G., Development of turbulence models for shear flows by a double expansion technique, Physics of Fluids A: Fluid Dynamics, Vol 4, No 7, 1510-1520, 1992.

[31] Crookston, BM., Labyrinth Weirs. PhD thesis, Utah State University, Logan, Utah, 2010.

[32] Indlekofer, H., Rouve, G., Discharge over polygonal weirs. ASCE, Journal of Hydraulic Engineering, Vol 101, No 3, 385- 401, 1995. 